Original Research Article

\title{
Adverse drug reactions monitoring of anticoagulant drugs used in cardiac coronary care unit of a tertiary care hospital
}

\author{
Sugandha Kassere $^{1}$, Juhi Kalra ${ }^{1}$, Anurag Rawat ${ }^{2}$, Saurabh Kohli ${ }^{1}$ *
}

\begin{abstract}
${ }^{1}$ Department of Pharmacology,
${ }^{2}$ Department of Cardiology, Himalayan Institute of Medical Sciences, Swami Rama Himalayan University, Dehradun, Uttarakhand, India

Received: 14 September 2019 Accepted: 17 October 2019

\section{*Correspondence to: \\ Dr. Saurabh Kohli, \\ Email: drskohli@gmail.com}

Copyright: (C) the author(s), publisher and licensee Medip Academy. This is an openaccess article distributed under the terms of the Creative Commons Attribution NonCommercial License, which permits unrestricted noncommercial use, distribution, and reproduction in any medium, provided the original work is properly cited.
\end{abstract}

\begin{abstract}
Background: Cardiovascular diseases are one of the leading causes of morbidity and mortality worldwide. Anticoagulants are the most commonly implicated drugs, used in cardiology unit and they are responsible for a majority of adverse drug reactions (ADRs). The objective of the present study was to evaluate the pattern of ADRs reported with anticoagulant drugs used in the cardiology unit of a tertiary care hospital.

Methods: This observational prospective study was undertaken from September 2017 to August 2018. Causality assessment of ADRs was assessed using the WHO and Naranjo scale of probability. The severity was assessed by modified Hartwig and Siegel scale, and preventability of ADRs was assessed by Schumock and Thornton scale.

Results: Out of the total forty-one ADRs recorded, $40(97.56 \%)$ were mild and $1(2.44 \%)$ was reported as severe on the Hartwig and Siegel severity scale. Hematuria $(68.29 \%)$ was the most common ADR followed by hemoptysis (14.63\%). Among all anticoagulants, low molecular weight heparin was associated with the majority of ADRs (85.37\%). The WHO causality and Naranjo Scale revealed that maximum of the ADRs $(\sim 80 \%)$ were possible. All ADRs reported was Type "A" reactions according to Wills and Brown classification of ADRs. Majority of ADRs (97.56\%) were probably preventable. Conclusions: In the present study, hematuria was the most common ADR reported. Among all anticoagulants, Low molecular weight heparin accounted for the majority of ADRs followed by acenocoumarol and heparin. Intensive monitoring and frequent reporting need to be done in cardiac units to improve patient safety.
\end{abstract}

Keywords: ADRs, Anticoagulants, Cardiovascular disease, Pharmacovigilance

\section{INTRODUCTION}

Adverse drug reactions (ADRs) have been defined by World Health Organization as, "a response to a drug that is noxious and unintended and first occurs at doses normally used in human beings for the prophylaxis, diagnosis, and treatment of disease, or for modification of physiological function". It is worldwide accepted that not a single drug is completely free from adverse effects and even the safest of the drugs can be associated with ADRs. ADRs are well-known effects of a drug. Worldwide, the overall incidence of ADRs is 6.5\%. They are considered to be a leading cause of morbidity and mortality worldwide and also lead to increased economic burden. $^{2-5}$

Cardiovascular diseases like hypertension, ischaemic heart disease, and congestive heart failure are the major causes of morbidity and mortality all over the world. Cardiac patients are often prescribed multiple drugs and have a very high risk for developing ADRs. For double vessel disease or triple vessel disease, surgical procedures such as percutaneous transluminal coronary angioplasty are the mainstay of the treatment. ${ }^{6-8}$

Anticoagulants are one of the most commonly prescribed drugs to cardiac patients admitted in the coronary care 
unit and are responsible for a number of ADRs. The ADRs caused by anticoagulants lead to significant comorbidities around the world. ${ }^{9}$ Anticoagulants like low molecular weight heparin and heparin are frequently used parental anticoagulants used in myocardial infarction (ST-elevation myocardial infarction, non-ST-elevation myocardial infarction). Anticoagulants can be associated with a number of adverse effects and drug interactions, many of them being serious these include bleeding, hematuria, heparin-induced thrombocytopenia, alopecia, osteoporosis, hypersensitivity reaction etc. ${ }^{10}$ Since cardiac disorders mostly require long term therapy and use of multiple drugs, this can predispose to ADRs. Hence, it is important that active pharmacovigilance would be done for this group of drugs.

\section{METHODS}

This prospective observational study was undertaken by the Department of Pharmacology in collaboration with the Department of Medicine (Cardiology) over a period of twelve months from September 2017 to August 2018. Ethical approval was taken from the Institutional ethics committee. A total of 41 ADRs were reported in patients due to anticoagulants, these were included in the study after taking prior informed consent.

\section{Inclusion criteria}

Patients of age above 18 year with either gender were admitted in cardiac coronary care unit.

\section{Exclusion criteria}

Patients with age less than 18 years with intentional or accidental poisoning and with a history of drug abuse were excluded.

The classification of ADRs was done using "Wills and Brown classification". "Causality assessment of ADRs was assessed using the WHO and Naranjo scale of probability. ${ }^{12,13}$ The severity was assessed by modified Hartwig and Siegel scale, and preventability of ADRs was assessed by Schumock and Thornton scale. ${ }^{14,15}$ The collected data was analyzed using available statistical software Microsoft Excel and SPSS version 20.0, (IBM). Descriptive data were presented in the form of rate, percentage, and frequency and depicted in the form of bar diagram and pie charts and tables. The ADRs were recorded on the 'Suspected Adverse Drug Reaction Reporting Form Version 1.2', and then reported using the Vigiflow software.

\section{RESULTS}

A total of 41 ADRs were reported with the use of anticoagulant drugs. Out of 41 ADRs, 27 (65.85\%) were reported in patients above 60 years of age, followed by 14 ADRs (34.15\%) in patients of age group $40-59$ years
(Figure 1). Polypharmacy was common and out of the 41 ADRs reported $(97.5 \%)$ were on 5 or more drugs.

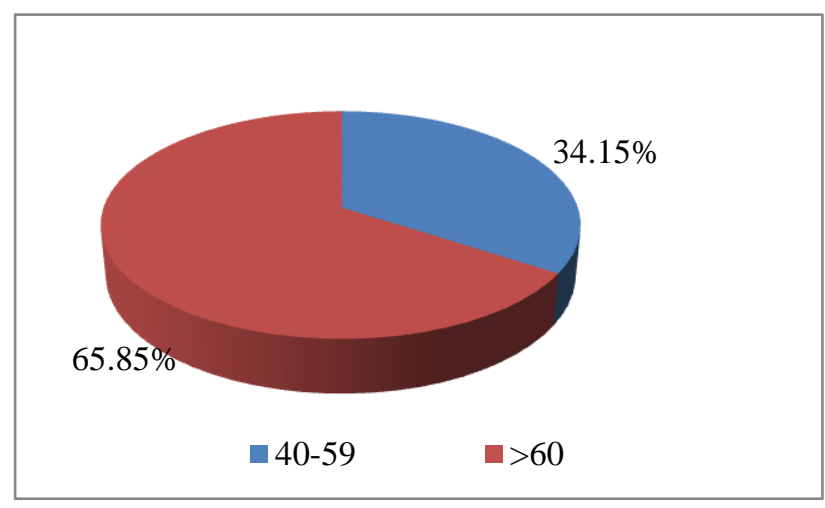

Figure 1: Age distribution of ADRs.

Hematuria (68.29\%) was the most common ADR reported in patients, followed by hemoptysis (14.63\%), petechiae over injection site $(12.20 \%)$, intracranial bleed $1(2.44 \%)$, and hematoma over femoral vein puncture site (2.44\%) (Figure 2).

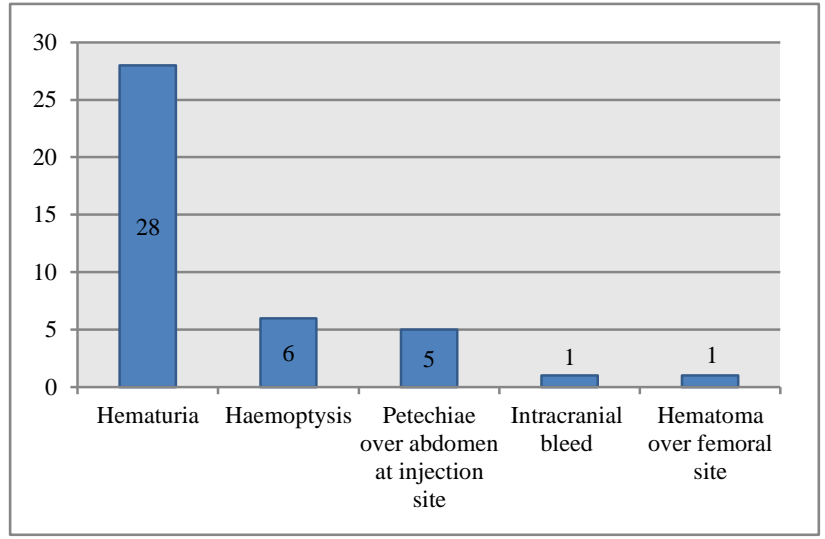

Figure 2: ADRs reported with the use of anticoagulant drugs at our critical care unit.

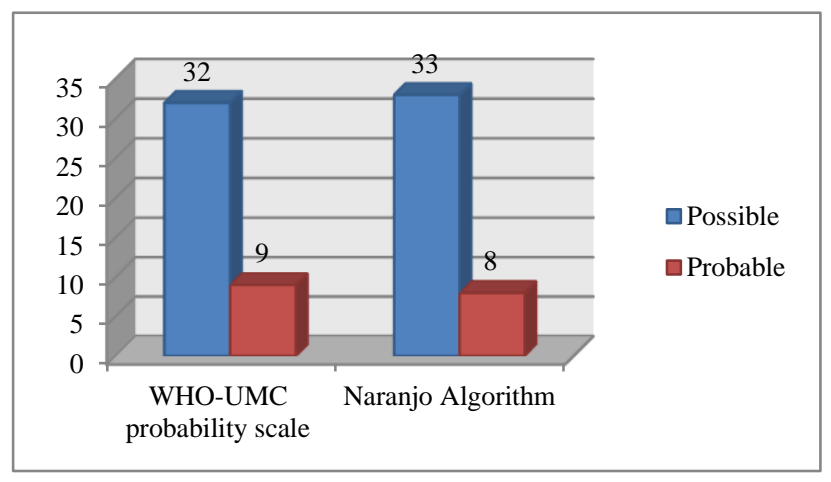

Figure 3: Causality assessment of ADRs according to WHO-UMC probability scale and Naranjo algorithm.

Assessment of ADRs using WHO-causality scale revealed that $32(78.05 \%)$ were "possible" and 9 
(21.95\%) were "probable", whereas Naranjo scale for accessing the probability revealed $33(80.49 \%)$ were "possible" and 8 (19.51\%) to be "probable" (Figure 3).

Low molecular weight heparin was associated with (85.37\%) ADRs, followed by acenocoumarol (7.32\%), heparin $(4.88 \%)$, fixed drug combinations $(2.44 \%)$ for one. Two patients received Heparin and both developed ADRs (Table 1).

Table 1: Number of ADRs reported with suspected class of drug.

\begin{tabular}{|l|l|}
\hline Suspected class of drug & $\begin{array}{l}\text { No. of ADRs (\%) } \\
\text { reported due to } \\
\text { suspected class of drug }\end{array}$ \\
\hline $\begin{array}{l}\text { Low molecular weight } \\
\text { heparin }(\mathbf{n}=35)\end{array}$ & 85.37 \\
\hline Acenocoumarol $(\mathbf{n}=3)$ & 7.32 \\
\hline Heparin $(\mathbf{n}=\mathbf{2})$ & 4.88 \\
\hline $\begin{array}{l}\text { Fixed drug combinations } \\
(\mathbf{n}=\mathbf{1})\end{array}$ & 2.44 \\
\hline
\end{tabular}

According to Wills and Brown classification of ADRs, all reported ADRs (100\%) were classified as "Type A" reactions. As per the severity scale by Hartwig and Siegel, forty ADRs were "mild" i.e., Level 2 and, only one case was "severe" i.e., Level 7 (Figure 4). According to Schumock Thornton scale for preventability of ADRs, forty ADRs were "probably preventable" and one was "definitely preventable" (Figure 5).

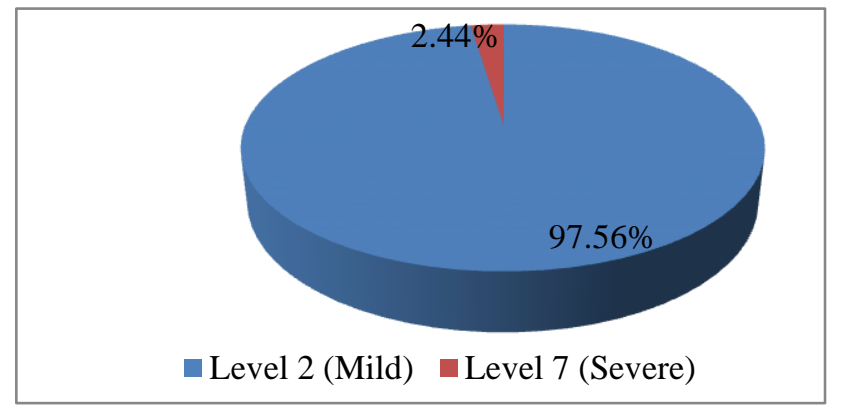

Figure 4: Severity of reported ADRs by Hartwig and Seigel scale.

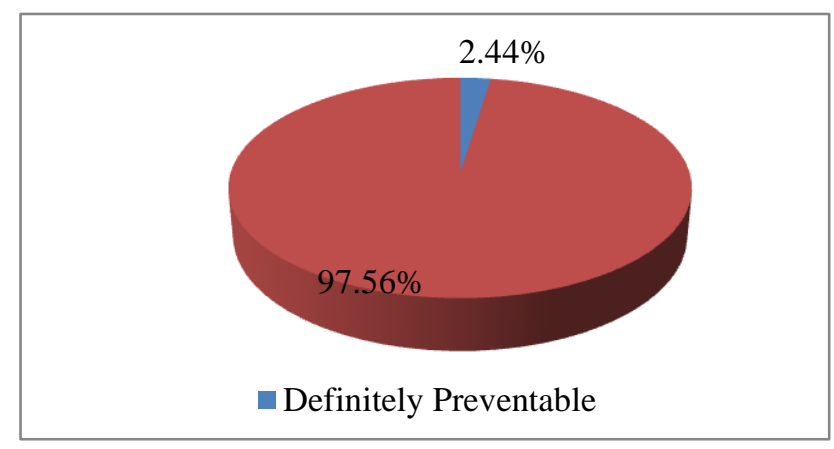

Figure 5: Preventability of ADRs according to Schumock Thornton scale.

\section{DISCUSSION}

In our study, the maximum of ADRs (65.85\%) were observed in patients with age more than 60 years (Figure 1). Earlier studies have revealed higher incidences (59.54\%) of ADRs in patients of $>60$ years of age than any other age group. ${ }^{16}$ The higher number of ADRs in the old age can be due to the altered pharmacokinetics like a decline in renal function and hepatic function. Polypharmacy is also common in this age group and can contribute to increase number of ADRs. ${ }^{17}$ The most frequently reported ADR in our study were hematuria $(68.29 \%)$ because bleeding is reported to be the most common side effect of parenteral anticoagulant therapy. This was followed by hemoptysis (14.63\%) and petechiae over injection site (12.20\%) (Figure 2). In an earlier study, hematuria was responsible for (14.29\%) of ADRs. ${ }^{18}$ However, another study reported a much higher incidence $(65 \%)$ of hematuria. ${ }^{19}$ The anticoagulant drug implicated in causing most of the ADRs in our study was low molecular weight heparin $(85.37 \%)$ followed by acenocoumarol $(7.32 \%)$, heparin $(4.88 \%)$. The apparent increased incidence of ADRs due to low-molecularweight heparin (LMWH) can be explained by the much more frequent use of LMWH in the study population. In a prospective study, low molecular heparin contributed to $10.5 \%$ of total ADRs. ${ }^{20}$ In our study, we compared the causality based on WHO-UMC scale and Naranjo algorithm (Figure 3). Naranjo probability scale is the generally accepted and most widely used methods for causality assessment in clinical practice as it offers a simple methodology. However, Pharmacovigilance Programme of India follows WHO-UMC assessment scale as this scale focus upon the clinical-pharmacologic aspects. $^{21}$ The WHO-UMC scale analysis in our study revealed that the majority of the reported ADRs (78.05\%) were "possible" and 21.95\% were "probable". A study conducted at the adverse drug reaction monitoring center of a tertiary care hospital, revealed that $62 \%$ ADRs were "possible", $28.2 \%$ certain and $6.8 \%$ were "probable". 7 While as per the Naranjo algorithm, in our study, $80.49 \%$ of the reported ADRs were categorized as "possible" while $19.51 \%$ of the ADRs were categorized as "probable". Similar results were observed in a study by Palaniappan et al where the majority of ADRs (68.8\%) were "possible" and $29.7 \%$ were "probable". There was no significant difference observed in the causality assessment with both scales. Most of the ADRs were possible because these ADRs had a reasonable time relationship with the drug intake.

As per the modified Hartwig and Seigel severity scale, forty $(97.56 \%)$ ADRs were categorized as "mild" (level 1) where ADRs not require change in the treatment and one $(2.44 \%)$ of the ADRs were "severe" (level 7) where the patient died due to intracranial bleed (Figure 4). In the present study, all the reported ADRs were classified as "Type A" as per the Wills and Brown classification of ADRs. Since these reactions were augmented a dose alteration may be done and more careful monitoring can 
prevent these inevitable ADRs in the future. According to the preventability criteria by Schumock and Thornton, 40 of the ADRs were "probably preventable" and one ADR was "definitely preventable" in which patient died due to intracranial bleed (Figure 5). This is similar to a study which showed that $70 \%$ of anticoagulant associated ADRs were potentially preventable.9 The death could have been prevented. The patient was 69 years of age and was consuming acenocoumarol (Acitrom) on her own, based on her previous prescription from elsewhere and without any consultations from physicians at our hospital. She presented to us in emergency in a state of unconsciousness. Patient education at the time of handing over the prescription can definitely prevent such mortality. A close follow-up and monitoring must be mandated for all patients on oral anticoagulants. Therapeutic drug monitoring must be done whenever facilities are available to prevent deaths for drugs like acenocoumarol.

ADRs such as hematuria, hemoptysis, petechiae over injection site are dose-dependent ADRs. However, to prevent fatal outcomes like stroke, arrhythmias, sudden cardiac death we have to use anticoagulants, thus, enhancing the possibility of augmented ADRs. These have to be used as per the American Heart Association guidelines for patients of coronary angioplasty and myocardial infarction. ${ }^{22}$ Additionally, the use of antiplatelet drugs is also recommended and the combination of these two drugs further increases the possibility of bleeding. This may have contributed to ADRs like hematuria and hemoptysis as some of the ADRs encountered in our study.

\section{CONCLUSION}

In the present study, the most common ADR reported was hematuria and LMWH was the most common drug implicated. Apparently, we analyzed that low molecular weight heparin was used in the majority of the patients as compared to heparin. Most of the ADRs were preventable but unavoidable because anticoagulants have to be given to the patients as a part of the treatment protocol. Intensive monitoring and frequent reporting are needed for all patients in critical care unit to reduce morbidity and mortality. Also, there is a need for very consistent and robust active pharmacovigilance in patients suffering from cardiovascular diseases who are admitted to the cardiac care unit and undergoing interventions. Active surveillance should be done to monitor ADRs effectively and to prevent the ADRs efficiently in order to avoid serious and fatal outcomes.

\section{Limitation}

The present study had limitation that they could not save the patient with intracranial bleeding despite our best efforts, as the patient came to us very late.

\section{ACKNOWLEDGEMENTS}

I am highly thankful to the Department of Pharmacology and Department of Cardiology for their cooperation. I am also very thankful to the Himalayan Institute of Medical Sciences for providing all the necessary support for this study.

\section{Funding: No funding sources}

Conflict of interest: None declared

Ethical approval: The study was approved by the Institutional Ethics Committee

\section{REFERENCES}

1. World Health Organization. Safety of medicinesadverse drug reactions. 2018. Available at: https:// www.who.int/medicines/regulation/medicines-safety /M_SBN_Jun18.pdf. Assessed on 12 July 2019.

2. Gor A, Desai S. Adverse drug reactions (ADR) in the in patients of medicine department of a rural tertiary care teaching hospital and influence of pharmacovigilance in reporting ADR. Indian $\mathbf{J}$ Pharmacol. 2008;40(1):37-40.

3. Akalu S, Belavadi N. Pattern of adverse drug reaction to antiepileptic drugs in a tertiary care hospital. Int $\mathbf{J}$ Basic Clin Pharmacol. 2017;6(9):2219-23.

4. Sahu R, Yadav R, Prasad P, Roy A, Chandrakar S. Adverse drug reactions monitoring: prospects and impending challenges for pharmacovigilance. Springer Plus. 2014;3(1):695-8.

5. Chan S, Ang X, Sani L, Ng H, Winther M, Liu J, et al. Prevalence and characteristics of adverse drug reactions at admission to hospital: A prospective observational study. $\mathrm{Br} \mathrm{J}$ Clin Pharmacol. 2016;82(6):1636-46.

6. Gholami K, Ziaie S, Shalviri G. Adverse drug reactions induced by cardiovascular drugs in outpatients. Pharm Pract. 2008;6(1):51-5.

7. Palaniappan $M$, Selvarajan $S$, George $M$, Subramaniyan G, Dkhar S, Pillai A, et al. Pattern of adverse drug reactions reported with cardiovascular drugs in a tertiary care teaching hospital. J Clin Diagn Res. 2015;9(11):1-4.

8. Buttar H, Li T, Ravi N. Prevention of cardiovascular diseases: Role of exercise, dietary interventions, obesity and smoking cessation. Exp Clin Cardiol. 2005;10(4):229-49.

9. Piazza G, Nguyen T, Cios D, Labreche M, Hohlfelder B, Fanikos J, et al. Anticoagulationassociated Adverse Drug Events. Am J Med. 2011;124(12):1136-42.

10. Tripathi K. Essentials of Medical Pharmacology. 8th ed. New Delhi: Jaypee Brothers Medical Publishers; 2018: 524-604.

11. Wills S, Brown D. A proposed new means of classifying adverse drug reactions to medicines. Pharm J. 1999;262:163-5.

12. The use of WHO UMC system for Standardized Case Causality assessment. Available at: http://www. 
who.int/medicines/areas/quality_safety/safety_efficac y/WHOcausality_assessment.pdf. Assessed on 10 August 2019.

13. Naranjo CA, Busto U, Sellers EM. A method for estimating the probability of adverse drug reactions. Clin Pharmacol Ther. 1981;30(2):239-45.

14. Hartwig SC, Siegel J, Schneider PJ. Preventability and severity assessment in reporting adverse drug reactions. Am J Hosp Pharm. 1992;49:2229-32.

15. Schumock GT, Thornton JP. Focussing on the preventability of adverse drug reactions. Hosp Pharm. 1992;27(6):538.

16. Wadhwa T, El Sheikh S, Rao PGM. Monitoring and reporting of adverse drug reactions due to cardiovascular drugs in patients admitted to a secondary care hospital in Northern Emirate- a prospective surveillance study. Indian J Pharm Pract. 2018;11(2):71-8.

17. Brahma D K, Wahlang JB, Sangma MC. Adverse drug reactions in the elderly. $J$ Pharmacol Pharmacother. 2013;4(2):91-4.

18. Amalia L, Anggadireja K, Aprami T, Septiani V. Prevalence of adverse drug reactions in CAD STEMI patients treated in the cardiac intensive care unit at the public hospital in Bandung, Indonesia. Sci Pharm. 2016;84(1):167-79.

19. Antoniewicz AA, Zapała H, Poletajew Z, Borówka A. Macroscopic hematuria a leading urological problem in patients on anticoagulant therapy: is the common diagnostic standard still advisable? ISRN Urol. 2012:710-34.

20. Cestac P, Bagheri H, Lapeyre-Mestre M, Si P, Fouladi A, Maupas E, et al. Utilisation and safety of low molecular weight heparins. Drug Saf. 2003;26(3):197-207.

21. Indian Pharmacopoeia Commission. Guidance document for Spontaneous Adverse Drug Reaction Reporting. World Health Organization, 2019. Available at: http://apps.who.int/medicinedocs/documents/s23300e n/s23300en.pdf. Assessed on 16 August 2019.

22. January CT, Wann LS, Calkins H, Chen LY, Cigarroa JE, Cleveland JS, et al. American College of Cardiology/American Heart Association Task Force on Clinical Practice Guidelines, and the Heart Rhythm Society. 2019 AHA/ACC/HRS Focused Update of the 2014 Guideline for Management of Patients with Atrial Fibrillation. 2019. Available at: https://www.acc.org/ /media/Non-Clinical/FilesPDFs-Excel-MS-Word-etc/Guidelines/2019/2019Afib-Guidelines-Made-Simple-Tool.pdf. Assessed on 7 August 2019.

Cite this article as: Kassere S, Kalra J, Rawat A, Kohli S. Adverse drug reactions monitoring of anticoagulant drugs used in cardiac coronary care unit of a tertiary care hospital. Int J Basic Clin Pharmacol 2019;8:2512-6. 